University of South Carolina

Scholar Commons

6-4-2014

\title{
Simulation and Analysis of Inhomogeneous Degradation in Large Format $\mathrm{LiMn}_{2} \mathrm{O}_{4} /$ Carbon Cells
}

\author{
Yiling Dai \\ Long Cai \\ Ralph E. White \\ University of South Carolina - Columbia, white@cec.sc.edu
}

Follow this and additional works at: https://scholarcommons.sc.edu/eche_facpub

Part of the Chemical Engineering Commons

\section{Publication Info \\ Published in Journal of The Electrochemical Society, Volume 161, Issue 8, 2014, pages E3348-E3356. (C) Journal of The Electrochemical Society 2014, The Electrochemical Society. \\ (C) The Electrochemical Society, Inc. 2014. All rights reserved. Except as provided under U.S. copyright law, this work may not be reproduced, resold, distributed, or modified without the express permission of The Electrochemical Society (ECS). The archival version of this work was published in Journal of The Electrochemical Society. \\ Publisher's Version: http://dx.doi.org/10.1149/2.040408jes \\ Dai, Y., Cai, L., \& White, R. E. (June 4 2014). Simulation and Analysis of Inhomogeneous Degradation in Large Format LiMn204/ Carbon Cells. Journal of The Electrochemical Society, 161 (8), E3348 - E3356. http://dx.doi.org/10.1149/2.040408jes}

This Article is brought to you by the Chemical Engineering, Department of at Scholar Commons. It has been accepted for inclusion in Faculty Publications by an authorized administrator of Scholar Commons. For more information, please contact digres@mailbox.sc.edu. 

Format $\mathrm{LiMn}_{2} \mathrm{O}_{4} /$ Carbon Cells

\author{
Yiling Dai, Long Cai," and Ralph E. White**,z \\ Department of Chemical Engineering, University of South Carolina, Columbia, South Carolina 29208, USA
}

\begin{abstract}
Degradation phenomena are not distributed uniformly in a large-format cell. To better understand the inhomogeneous degradation in large-format cells, a two-dimensional model was developed for a $\mathrm{LiMn}_{2} \mathrm{O}_{4}$ (LMO)/Carbon cell. The model includes both the nonuniform porous electrode properties and the electrode mismatch. The simulation results show that when the anode edge is extended over the cathode edge, the LMO particles near the edge suffer larger potential difference, larger charge/discharge depth, and higher insertion-induced stress. Therefore, the predicted loss of LMO is more pronounced near the edge as has been seen experimentally. The influence of different design adjustable parameters (such as: the anode extension length, the capacity ratio, the porosity, and the electrode thickness) and electrolyte properties (such as: the diffusion coefficient and the ionic conductivity) on the cathode performance. Among them, the over-potential behavior of the cathode is most sensitive to the extent of the electrode mismatch. Larger anode extensions will increase the possibility of the LMO degradation at the cathode edge. This suggests that a longer extension of the anode is not better for improvement of cell life. An optimal design of the anode extension length should be carried out. (C) 2014 The Electrochemical Society. [DOI: 10.1149/2.040408jes] All rights reserved.
\end{abstract}

Manuscript submitted March 27, 2014; revised manuscript received June 4, 2014. Published June 17, 2014. This paper is part of the JES Focus Issue on Mathematical Modeling of Electrochemical Systems at Multiple Scales.

Since the first commercial Li-ion batteries were released in 1991, they have become the most desirable power sources for portable consumer electronics. To meet the challenges of global warming and the finite nature of fossil fuels, Li-ion batteries are being intensively pursued for transportation applications and stationary storage of renewable energy. ${ }^{1}$ For these applications, the required lifetime of Li-ion batteries is over than ten years. However, current batteries fall short of the lifetime requirement due to undesirable aging phenomena. $^{2-4}$

As the degradation of $\mathrm{Li}$-ion batteries is a complicated procedure, a complete understanding of degradation mechanisms is of critical importance to improve cell life. Numerous efforts have been devoted to the study of cell failure in the last twenty years, and several mechanisms have been proposed to account for the degradation. ${ }^{2,4}$ One of the most important causes of cell degradation is the loss of the cyclable lithium due to the lithium plating and the solid electrolyte interface (SEI) layer formation on the carbonaceous anode. ${ }^{5,6}$ Lithium plating causes serious safety problem of Li-ion batteries, which results in the dendritic growth and eventually forms the internal short-circuit. ${ }^{7,8}$ Lithium plating occurs when the local over-potential is below zero (versus $\mathrm{Li} / \mathrm{Li}^{+}$), specifically, when the cell is operated at high-current charging or at low temperature. To avoid that, Li-ion batteries are generally made with an excess anode capacity. However, if the cell geometry is not well designed, the lithium plating can still occur at the anode edge in a cell with excess anode capacity. ${ }^{8,9}$ Experiments have shown that an anode longer than the cathode by $1 \mathrm{~mm}$ can effectively prevent the lithium plating at the anode edge. However, this overlap design could induce a high local potential difference $(>4.3 \mathrm{~V}$ versus $\left.\mathrm{Li} / \mathrm{Li}^{+}\right)$at the cathode edge. ${ }^{10,11}$ The high potential difference will cause unexpected side reactions at the cathode edge. The SEI layer is mainly generated during the initial formation cycling of a fresh cell and prevents the further formation of the SEI film. But the damage of the SEI film due to the sink and expansion of the anode particle during cycling can still lead to new formation on the newly opened sites of the anode particle. The loss of active material is another important contribution to the cell's degradation. It has been found that most of the cathode active materials are not stable in common organic electrolytes. ${ }^{12,13}$ The dissolution of transition metal from the cathode active material into the electrolyte has been intensively reported. ${ }^{12-14}$ In addition, particle fracture of the active material has been observed due to electrochemical cycling. ${ }^{15-17}$ Particle fracture leads to the loss

\footnotetext{
*Electrochemical Society Active Member.

*** Electrochemical Society Fellow.

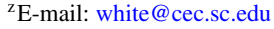

of the active material, causes the loss of cyclable lithium ions, and also increases the resistance. Furthermore, particle fracture can lead to losses in connection of the active material particle to the conductor. ${ }^{18}$

The cell degradation was found to be inhomogeneous with respect to both in thickness and planar directions of the cell electrodes. In the thickness direction, Kostecki et al. ${ }^{19}$ reported that the gradual structural degradation of the graphite was most serious on the electrode surface. A thicker layer of inorganic product was observed on the disordered carbon near the electrode/separator interface. Similarly, postmortem SEM images taken from a 18650 cell showed that particle fracture was more pronounced in the region closest to the separator region. ${ }^{20}$ On the other hand, Cai et al. ${ }^{21}$ recently examined the electrode degradation in the planar direction of a large-format $\mathrm{LiMn}_{2} \mathrm{O}_{4}$ (LMO)/graphite cell. It was found that the loss of LMO active material was more serious at the electrode edge.

However, it is always challenging to rationalize much observed inhomogeneous degradation behavior, especially for large-format batteries, which have highly non-uniform concentration and potential distributions in the planar direction. ${ }^{11}$ Mathematical modeling methods provide effective ways to test hypotheses and uncover what happens inside battery systems. For example, a pseudo-two dimensional (P2D) model based on porous electrode theory has been applied to study the inhomogeneous degradation in the thickness direction. ${ }^{7,22}$ In the P2D model, the gradients of the variables are assumed to be negligible in the other two directions, which are parallel to the current collectors. This assumption may be valid for small-scale cells, but is not reasonable for large-format cells. Multi-dimensional models are very desirable to understand different behaviors in a large-format cell. There are several studies that have developed the multi-dimensional model to examine the temperature or state of charge distribution across a large cell. ${ }^{23-28}$ However, cell misalignment and edge effects were ignored in these studies. Recently, Tang et al. ${ }^{8}$ developed a 2D model to investigate the lithium plating in a cylindrical cell with electrode misalignment. For simplicity, the electrode was considered as a thin film. Also, the electrolyte concentration was assumed to be constant. They found that the lithium plating issue was very sensitive to the cell geometry. Based on the theoretical study, they suggested anode extension as a simple but effective way to mitigate the lithium plating on the anode edge. This is commonly accepted in Li-ion batteries manufacturing.

However, the simulation work that systematically investigates the inhomogeneous degradation of porous electrode in a large-format cell has never been reported. In this work, we have developed a 2D mathematical model to explore the inhomogeneous degradation of a specified LMO electrode. This model includes both non-uniform porous 


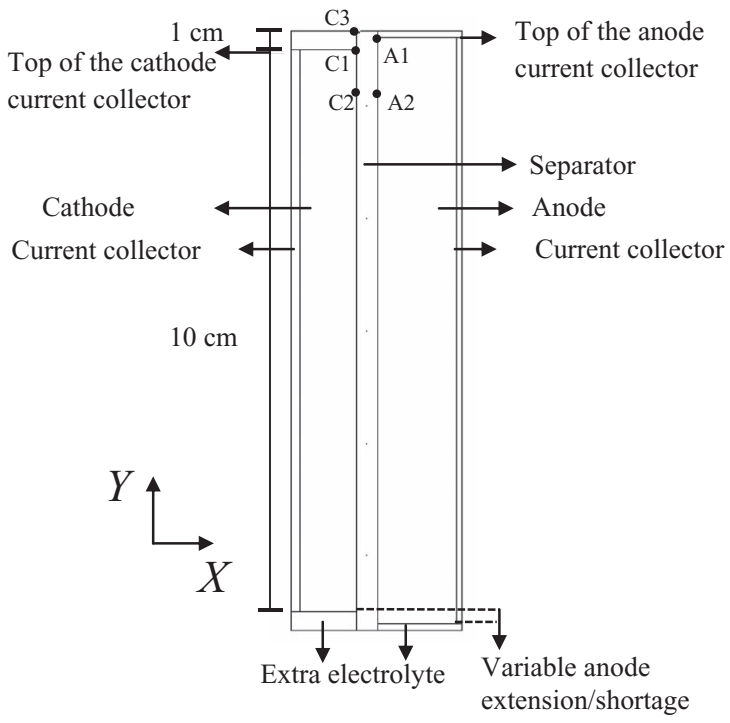

Figure 1. Schematic of a Li-ion battery in two-dimensional domain (not to scale).

electrode properties and edge effects on LMO electrode degradation. Our analysis is based on model predicted chemical, electrochemical, and mechanical situations that the cell has encountered.

\section{Model Development}

Figure 1 shows a two-dimensional schematic diagram of a Li-ion battery. The thickness direction (in-thickness) is denoted by X, and the in-plane direction (planar) is denoted by Y. The battery consists of two current collectors, a LMO cathode, a separator, a carbon anode, and electrolyte filled in the porous media. As in other studies, ${ }^{24,29}$ the terminal tabs are ignored in this work. Current is assumed to flow in and out uniformly from the top of the current collector. The P2D model is extended to a P3D model and solved in the 2-D domain shown in Figure 1. The planar length of the LMO electrode is $10 \mathrm{~cm}$. The planar length of the carbon electrode is varied in the study. The extension or shortage of the anode is identical at both edges. The length of the extra electrolyte on the sides of LMO electrode is $1 \mathrm{~cm}$. Other parameters of the cell can be found in Table I.

The P2D model has been applied to simulate the behavior of $\mathrm{Li}$ ion batteries in several papers. ${ }^{30-32}$ The mass balance and the charge

\section{Table I. Properties for the Active Materials.}

\begin{tabular}{ccc} 
& \multicolumn{2}{c}{ Values } \\
\cline { 2 - 3 } Parameters & LMO & Carbon \\
\hline$c_{\max }\left(\mathrm{mol} \mathrm{m}^{-3}\right)$ & $22860^{\mathrm{a}}$ & $30540^{\mathrm{a}}$ \\
$D_{s}\left(\mathrm{~m}^{2} \mathrm{~s}^{-1}\right)$ & $1.0 \times 10^{-13 \mathrm{a}}$ & $2.0 \times 10^{-13 \mathrm{a}}$ \\
$k_{L i}\left(\mathrm{~mol}^{-0.5} \mathrm{~m}^{2.5} \mathrm{~s}^{-1}\right)$ & $5.0 \times 10^{-10 \mathrm{c}}$ & $1.764 \times 10^{-11 \mathrm{~b}}$ \\
$R_{s}(\mathrm{~m})$ & $8.5 \times 10^{-6 \mathrm{a}}$ & $12.5 \times 10^{-6} \mathrm{a}$ \\
$\theta^{0}$ & $0.98^{\mathrm{d}}$ & $0.01^{\mathrm{d}}$ \\
$U(\mathrm{~V})$ & See Eq. A6 & See Eq. A7 \\
$E(\mathrm{GPa})$ & $10^{\mathrm{e}}$ & - \\
$v$ & $0.3^{\mathrm{e}}$ & - \\
$\Omega\left(\mathrm{mol} \mathrm{m}^{-3}\right)$ & $2.29 \times 10^{4} \mathrm{e}$ & -
\end{tabular}

balance are considered in both the solution phase and the solid phase. We only briefly introduce the model here, as follows. A detailed explanation of the porous electrode models can be found elsewhere. ${ }^{30-32}$

The mass balance for lithium ions in the electrolyte is given as follows:

$$
\frac{\partial\left(\varepsilon_{2, i} c_{e, i}\right)}{\partial t}=\nabla \cdot\left(D_{\mathrm{e}, \mathrm{eff}, i} \nabla c_{e, i}\right)+\left(1-t_{+}^{0}\right) a_{i} J_{i}, i=p, s, n, e
$$

where $\varepsilon_{2, i}$ is the porosity in cell component $i$ ( $i=p$ for the cathode, $i=s$ for the separator, and $i=n$ for the anode, $i=e$ for the extra electrolyte area), $c_{e}$ is the concentration of lithium ion, $D_{e, e f f}$ is the effective diffusivity of lithium ion in the electrolyte, $t_{+}^{0}$ is the transport number of lithium ion, $J_{i}$ is the pore wall flux of lithium ion on the surface of the active material, and $a_{i}$ is the specific surface area of active material particle which is defined as follows:

$$
a_{i}=\frac{3 \varepsilon_{1, i}}{R_{s, i}}
$$

where $\varepsilon_{1, i}$ is the volume fraction of active material in region $i$, and $R_{s, i}$ is the radius of active material particles. The potential in the solid phase, $\phi_{1}$, is given by Ohm's law as follows:

$$
\nabla \cdot\left(\sigma_{\mathrm{eff}, i} \nabla \phi_{1, i}\right)=a_{i} F J_{i}, i=p, n
$$

where $\sigma_{e f f, i}$ is the effective conductivity in the solid phase and $F$ is Faraday's constant.

The solution phase potential, $\phi_{2}$, is given by:

$$
\begin{aligned}
& \nabla \cdot\left(-\kappa_{e f f, i} \nabla \phi_{2, i}+\frac{2 R T\left(1-t_{+}^{0}\right) \kappa_{e f f, i}}{F} \nabla\left(\ln c_{e, i}\right)\right) \\
& \quad=a_{i} F J_{i}, i=p, s, n, e
\end{aligned}
$$

where $\kappa_{e f f, i}$ is the effective conductivity in the solution phase, $R$ is the gas constant, and $T$ is the temperature.

The pore wall flux of lithium ion, $J_{i}$, is described by the ButlerVolmer equation as follows:

$J_{i}=k_{L i, i} c_{s, \text { surf }, i}^{0.5}\left(c_{\max , i}-c_{s, \text { surf }, i}\right)^{0.5} c_{e}^{0.5}\left[\exp \left(\frac{\alpha_{a} F}{R T} \eta_{i}\right)-\exp \left(-\frac{\alpha_{c} F}{R T} \eta_{i}\right)\right]$

where $k_{L i, i}$ is the reaction rate constant, $c_{s, \text { surf }, i}$ is the surface lithium ion concentration of particles, and $c_{\max , i}$ is the maximum concentration of lithium ion in the particles. The pore wall fluxes in the extra electrolyte areas shown in Eqs. 1 and 4 are set to zero because no active material is present in these areas. The over-potential in region $i$ is given by:

$$
\eta_{i}=\phi_{1}-\phi_{2}-U_{i}
$$

where $U_{i}$ is the open-circuit potential in region $i$. The effective properties are discussed and presented in the Appendix.

The material balance in the particles can be written using Fick's second law as follows:

$$
\frac{\partial c_{s, i}}{\partial t}=\frac{1}{r^{2}} \frac{\partial}{\partial r}\left[D_{s, i} r^{2}\left(\frac{\partial c_{s, i}}{\partial r}\right)\right]
$$

The boundary conditions for the solid phase diffusion are given by:

$$
\begin{gathered}
-\left.D_{s, i} \frac{\partial c_{s, i}}{\partial r}\right|_{r=0}=0 \\
-\left.D_{s, i} \frac{\partial c_{s, i}}{\partial r}\right|_{r=R_{s, i}}=J_{i}
\end{gathered}
$$

To further reduce the computation cost, we applied a three-term polynomial approximation for the lithium ion concentration in solid phase: ${ }^{33}$

$$
\frac{d c_{s, \mathrm{avg}, i}}{d t}=-\frac{3 J_{i}}{R_{s, i}}, i=p, n
$$




$$
\begin{gathered}
\frac{d q_{s, \text { avg }, i}}{d t}=-\frac{30 D_{s, i} q_{s, \text { avg }, i}}{R_{s, i}^{2}}-\frac{45 J_{i}}{2 R_{s, i}^{2}}, i=p, n \\
c_{s, s u r f, i}-c_{s, \text { avg }, i}=\frac{8 R_{s, i} q_{s, \text { avg }, i}}{35}-\frac{R_{s, i} J_{i}}{35 D_{s, i}}, i=p, n
\end{gathered}
$$

where $c_{s, \text { avg, } i}$ is the volume-averaged concentration in the particle and $q_{s, \text { avg, } i}$ is the volume-averaged flux in the particle.

The lithium ion flux and the solution phase current at the current collector/electrolyte interfaces and the outer surfaces of the extra electrolyte are zero as follows:

$$
\begin{gathered}
\vec{n} \cdot\left(-D_{\mathrm{e}, \mathrm{eff}, \mathrm{i}} \nabla c_{e}\right)=0 \\
\vec{n} \cdot\left(-\kappa_{e f f, i} \nabla \phi_{2, i}+\frac{2 R T\left(1-t_{+}^{0}\right) \kappa_{e f f, i}}{F} \nabla\left(\ln c_{e, i}\right)\right)=0
\end{gathered}
$$

where $\vec{n}$ is the normal direction of the boundary.

Because the current is carried by the solution phase at the electrode/separator interface and electrode/flood electrolyte interface, the currents in the solid phase at these interfaces are zero:

$$
\vec{n} \cdot\left(-\sigma_{\mathrm{eff}, i} \nabla \phi_{1, i}\right)=0
$$

The current is applied at the top of cathode current collector, that is:

$$
-\sigma_{\mathrm{cc}, i} \frac{\partial \phi_{1, t o p, c}}{\partial Y}=I_{a p p}
$$

where $I_{a p p}$ is the applied current density, $\phi_{1, t o p, c}$ is the potential at the top of the cathode current collector.

The potential at the top of the anode current collector, $\phi_{1, t o p, a}$, is set to zero as the reference potential:

$$
\phi_{1, t o p, a}=0
$$

\begin{tabular}{|c|c|c|c|}
\hline \multirow[b]{2}{*}{ Parameters } & \multicolumn{3}{|c|}{ Values } \\
\hline & Positive & Separator & Negative \\
\hline$\varepsilon_{1}$ & $0.37^{\mathrm{a}}$ & - & $0.511^{\mathrm{a}}$ \\
\hline$\varepsilon_{2}$ & $0.416^{\mathrm{a}}$ & $0.45^{\mathrm{b}}$ & $0.36^{\mathrm{a}}$ \\
\hline$L(\mathrm{~m})$ & $145 \times 10^{-6 a}$ & $25 \times 10^{-6 \mathrm{~b}}$ & $85 \times 10^{-6}$ a \\
\hline$L_{c c}(\mathrm{~m})$ & $15 \times 10^{-6 \mathrm{f}}$ & - & $10 \times 10^{-6 \mathrm{f}}$ \\
\hline$\sigma\left(\mathrm{S} \mathrm{m}^{-1}\right)$ & $3.8^{\mathrm{a}}$ & - & $100^{\mathrm{a}}$ \\
\hline$\sigma_{c c}\left(\mathrm{~S} \mathrm{~m}^{-1}\right)$ & $3.78 \times 10^{7 \mathrm{f}}$ & - & $5.96 \times 10^{7 \mathrm{f}}$ \\
\hline Brugg & $1.5^{\mathrm{a}}$ & $1.5^{\mathrm{a}}$ & $1.5^{\mathrm{a}}$ \\
\hline$\alpha_{a}$ & & $0.5^{\mathrm{d}}$ & \\
\hline$\alpha_{c}$ & & $0.5^{\mathrm{d}}$ & \\
\hline$t_{+}^{0}$ & & $0.363^{\mathrm{a}}$ & \\
\hline$c_{L i^{+}}^{0}\left(\mathrm{~mol} \mathrm{~m}^{-3}\right)$ & & $1000^{\mathrm{a}}$ & \\
\hline$D\left(\mathrm{~m}^{2} \mathrm{~s}^{-1}\right)$ & & See Eq. A3 & \\
\hline$\kappa\left(\mathrm{mol} \mathrm{m}^{-3}\right)$ & & See Eq. A4 & \\
\hline$F\left(\mathrm{C}_{\text {equiv }^{-1}}\right)$ & & 96487 & \\
\hline$R\left(\mathrm{~J} \mathrm{~mol}^{-1} \mathrm{~K}^{-1}\right)$ & & 8.314 & \\
\hline$T(\mathrm{~K})$ & & 298.15 & \\
\hline
\end{tabular}

The cell voltage, $V_{\text {cell }}$, is determined by:

$$
V_{\text {cell }}=\phi_{1, t o p, c}-\phi_{1, t o p, a}
$$

The values of the model parameters are presented in Table II.

Table II. Model Parameters.

\footnotetext{
${ }^{a}$ obtained from Ref. 41;

b obtained from Ref. 42;

cobtained from Ref. 43;

dassumed:

eobtained from Ref. 37;

${ }^{\mathrm{f}}$ obtained from Ref. 26.
}

\section{Results and Discussion}

We first conducted a simulation for a full cell with a shorter anode. Then, the model is applied to a cell with a $1 \mathrm{~mm}$ extension of the anode over the cathode on each side. Finally, simulations were run to show the influence of the adjustable design parameters and the electrolyte properties on the cathode performance in a cell with the anode extension.

Shortage of anode electrode.- One of the major problems of Liion batteries is the lithium plating on the anode. It not only causes the loss of the cell capacity, but also causes a cell safety problem due to the growth of lithium dendrite, which may result in an internal short in the cell. Previous experimental and theoretical works have shown that lithium plating occurs seriously at the anode edge, if the anode is shorter than the cathode. ${ }^{8,9}$ A simulation was run with a shorter anode to elaborate this phenomenon. Figure $2 \mathrm{a}$ shows the potential difference between the solid phase and the electrolyte, $\phi_{1}-\phi_{2}$, at the edge point, which is at the top inner corner of the anode (Point A1 shown in Figure 1) as well as at an inner point (Point A2 shown in Figure 1) of the anode during cell charging. In this case, the anode edge is $0.4 \mathrm{~mm}$ shorter than the cathode edge. The distance between the edge and inner points is about $1 \mathrm{~cm}$. The charge rate is $1 \mathrm{C}$. The cell voltage is also plotted as $4.2-\mathrm{V}$ cell to indicate when the cell reaches the cutoff charge voltage. Similar to previous theoretical studies, ${ }^{8}$ Figure 2 a shows that the potential difference at the edge point is lower than the one at the inner point. Furthermore, the potential difference at the anode edge is less than zero before the cell voltage reaches the cutoff charge voltage $(4.2 \mathrm{~V})$. This indicates that lithium plating will occur first on the anode edge as expected.

The electric conductivity of the solid phase in the two electrodes is high enough compared to the electrolyte, therefore, the potential in the solid phase is almost uniform in the whole cathode and anode, respectively. It is reasonable to believe that the deviation of potential difference in Figure 2a is mainly caused by the electrolyte potential. During charging a cell with a shorter anode, the simulated electrolyte potential $\left(\phi_{2}\right)$ at $\mathrm{t}=1000 \mathrm{~s}$ is plotted in Figure $2 \mathrm{~b}$. There is a very large potential drop near the edge of the electrode in the planar direction of the electrodes. The electrolyte potential in the extra electrolyte area is much lower (in absolute value) than the inner area of the electrodes. This kind of potential distribution remains during the whole charging process. Therefore, it is expected that the deviation of potential difference between the inner and the edge points happens as shown in Figure 2a. Such electrolyte potential distribution is caused by a local galvanic cell in the cathode, as discussed in previous work. ${ }^{10,11}$ During charging a cell with a shorter anode, lithium ions de-insert faster from the LMO particles at the inner points than from those at the edge points. This is because that the inner cathode part is exposed to more carbon. Herein, the potential of LMO increases more rapidly at the inner point than at the edge point. The potential gradient between inner and edge points causes lithium ion current flow parallel to the plane of the electrodes. As shown in Figure 2b, at the electrode edge there is small current flow in the direction parallel to the plane of the electrodes. The arrows in Figure $2 b$ represent the direction and magnitude of the current flow in the electrolyte. This current causes ohmic drop in the direction parallel to the plane of the electrodes.

Figure $2 \mathrm{c}$ shows the potential differences along the interfaces of separator/anode (Sep/Anode) and anode/current collector (Anode/CC) at the end of charge. Figure $2 \mathrm{c}$ indicates that the potential difference distribution is not uniform both in the planar (along the horizontal axis in Figure 2c) and in-thickness directions (gap between the two curves in Figure 2c). Obviously, the potential difference distribution is larger in the planar direction. The potential difference at the edge is far below zero, at which the lithium plating is favor to occur.

Extension of the anode electrode.- As in the discussion above, the practice of manufacturing cells with a shorter anode than the cathode is avoided in order to prevent lithium plating on the anode 
(a)

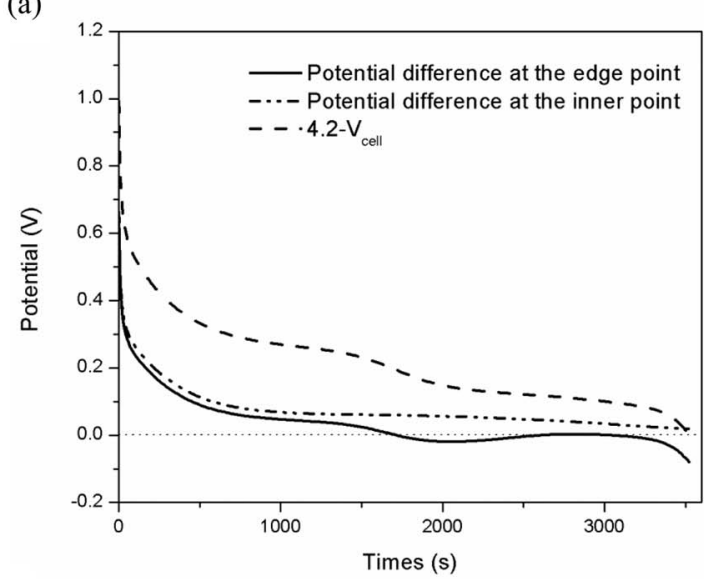

(b)

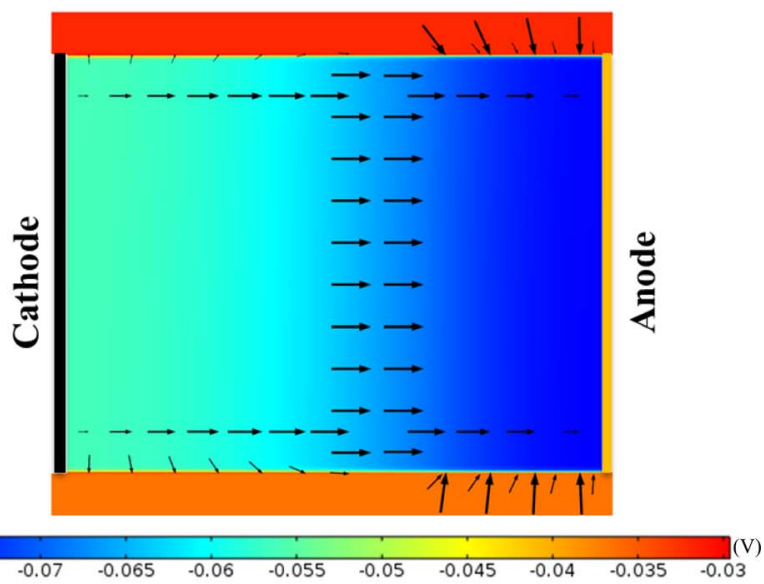

(c)

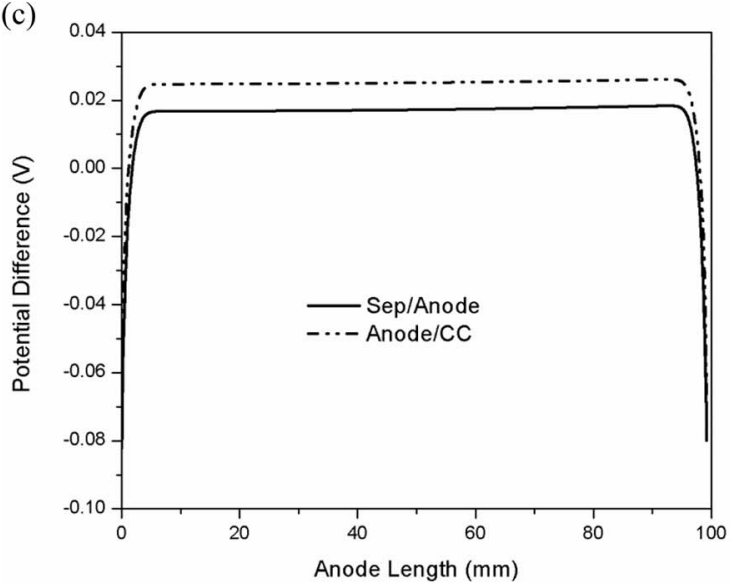

Figure 2. (a) The potential difference, $\phi_{1}-\phi_{2}$, at the edge point as well as at the inner point of anode and the cell voltage as function of time; (b) electrolyte potential, $\phi_{2}$, distribution and current flow in the cell (c) The potential difference at the interfaces between separator and anode (Sep/Anode) and between anode and current collector (Anode/CC) at the end of the first charge for a cell with a anode $0.4 \mathrm{~mm}$ shorter than the cathode.

edge. Experiments have shown that an anode longer than the cathode by $1 \mathrm{~mm}$ can effectively prevent the lithium plating. ${ }^{8,9}$ We investigate the effect of anode extension on preventing lithium plating in a cell with an anode extension of $1 \mathrm{~mm}$ over the cathode in the following study.

Similarly to Figure 2a, Figure 3 a shows the potential difference $\left(\phi_{1}-\phi_{2}\right)$ at the edge point as well as at the inner point of the anode as a function of time during a $1 \mathrm{C}$ charge. In contrast to the shorter- (a)

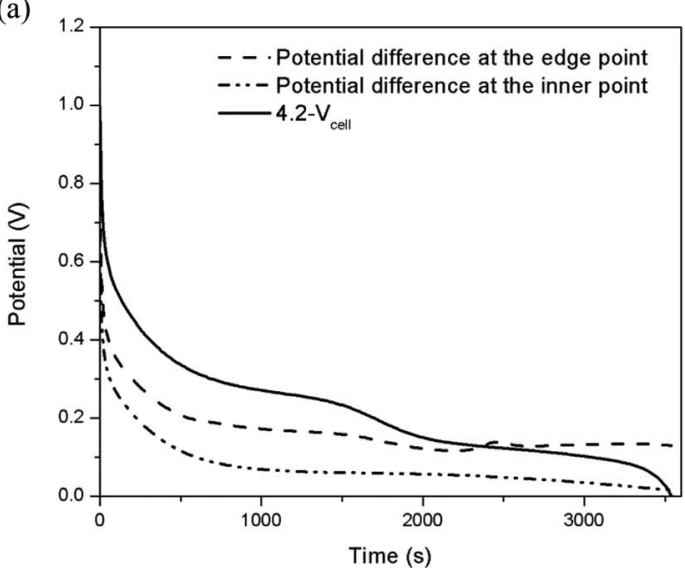

(b)

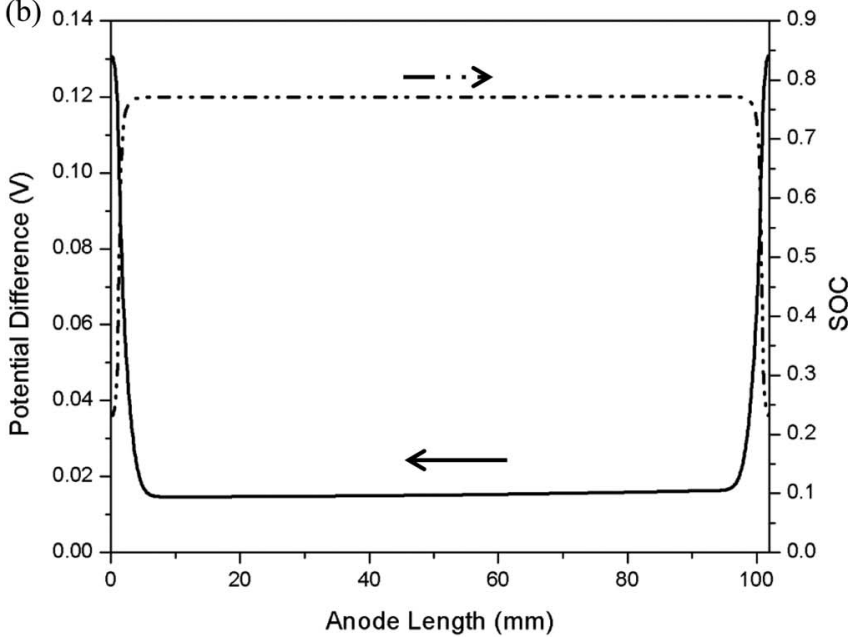

Figure 3. (a) The potential difference, $\phi_{1}-\phi_{2}$, at the edge point as well as at the inner point of anode and the cell voltage as function of time; (b) The potential difference (right) and SOC (left) distribution along the anode/separator interface at the end of first charge for a cell with a $1 \mathrm{~mm}$ anode extension over the cathode.

anode case, this figure shows that the potential difference at the edge is never less than zero during a $1 \mathrm{C}$ charge. Also, it shows that the potential difference curve at the edge point is higher than the one at the inner point. This phenomenon has also been observed in experimental work. ${ }^{11}$ Similar to Tang's model, ${ }^{8}$ this simulation result indicates that the anode extension can mitigate the lithium plating at the edge of the anode. It should be noted that the potential difference at inner points shows no significant change in the two different cases (with shorter anode and longer anode). This indicates that the edge effect is limited to the edge area.

Figure $3 \mathrm{~b}$ shows the potential difference along the Separator/Anode interface at the end of charge (left axis). Like the shorteranode case, the potential difference has a non-uniform distribution in the planar direction. This is similar to the previous experiment observation in a cell with similar cell geometry which was reported in Refs. 10,11. However, the potential difference shows an inverse distribution type. This indicates that the edge effect is very sensitive to electrode mismatch. Figure $3 \mathrm{~b}$ also shows the state of charge (SOC) distribution along the separator/anode interface at the end of a $1 \mathrm{C}$ charge (right axis). The SOC in this study is referred to as $c_{s, \text { avg }} / c_{\max }$. As shown in Fig. 3b, there is a big SOC jump near the edge of the anode. The SOC in the inner part of the anode is about 0.77 , whereas the SOC at the edge of the anode is about 0.23 , which is just a little higher than the one before the cell was charged. This indicates that the edge of the anode is less-utilized for lithium insertion than in the 


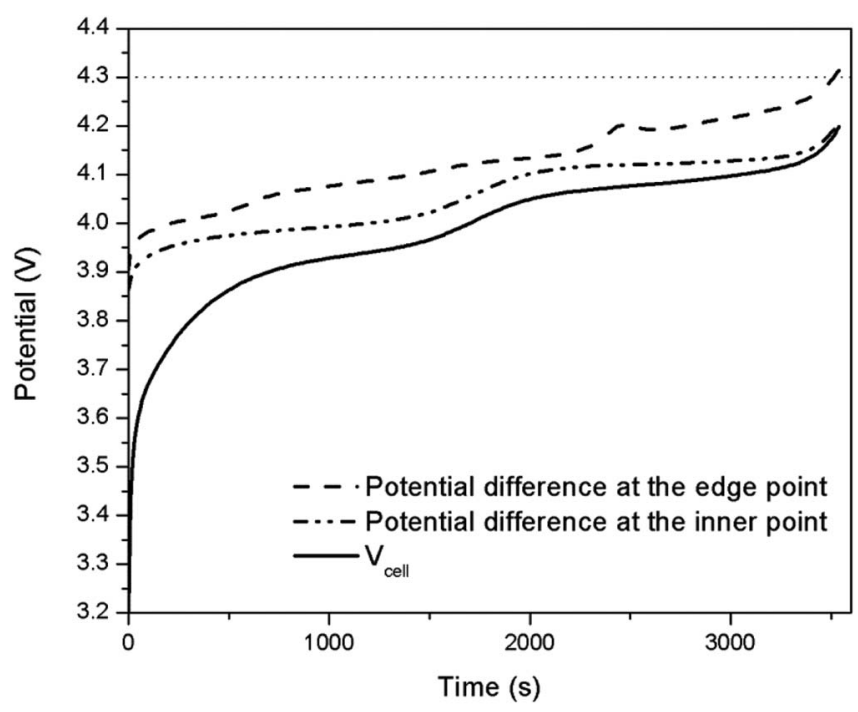

Figure 4. The potential difference, $\phi_{1}-\phi_{2}$, at the edge point as well as at the inner point of cathode and the cell voltage as function of time during $1 \mathrm{C}$ charge for a cell with a $1 \mathrm{~mm}$ anode extension over the cathode.

case with anode extension. This is different from previous work as reported by Tang et al. ${ }^{8}$ In their model, the electrode is treated as thin film, which has a limited reaction surface. As the lithium ion is saturated at the surface layer of thin film in the center of electrode, the insertion reaction will shift to edge. Therefore, the utilization of edge area is high in their study. But in a porous electrode, it is not supposed to happen as shown in this study.

As shown above, the lithium plating at the anode edge problem can be prevented by extending the anode over the cathode edge. It is also important to investigate the performance of the LMO cathode in a cell with a longer anode. Figure 4 shows the potential difference at the edge point (Point $\mathrm{C} 1$ shown in Figure 1) and the inner point (Point $\mathrm{C} 2$ shown in Figure 1) of the cathode during a $1 \mathrm{C}$ charge. The distance between the edge and inner points is about $1 \mathrm{~cm}$. As shown in Figure 4, the potential difference at the edge is higher than the potential difference at the inner point. Because the solid phase is more conductive than the liquid one, the variance of potential difference is mainly caused by the electrolyte potential as discussed above. Moreover, the potential difference at the edge is over $4.3 \mathrm{~V}$ at the end of a $1 \mathrm{C}$ charge, which may lead to electrolyte oxidation at the cathode edge. It was found that the electrolyte oxidation will induce the LMO degradation. ${ }^{13}$ Therefore, LMO will deteriorate more seriously at the cathode edge.

Figure 5 shows the SOC during cycling at two different positions: at the edge and inner points of the cathode. The cell was cycled at $1 \mathrm{C}$ charge/discharge between $3.0 \mathrm{~V}$ and $4.2 \mathrm{~V}$. It can be seen from Figure 5 that the LMO particles at the edge suffer a little wider SOC range. These particles are both charged to lower SOC (over-charge) and discharged to higher SOC (over-discharge). As discussed earlier, the potential difference is higher at the electrode edge during charge which leads to overcharge in ther particles at the cathode edge. The over-discharge also occurs in the particles at the cathode edge due to its exposure to more carbon. It was found that the over-discharge in a cell with a LMO cathode will lead to J-T distortion in the LMO particles. ${ }^{34}$. The higher SOC at the end of discharge shown in Figure 5 will increase the possibility of J-T distortion at the cathode edge. From this point of view, the LMO degradation is more pronounced at the edge.

Mechanical degradation such as particle fracture in the active material is another contribution to the cell capacity loss. lithium insertion/de-insertion will induce stress inside the active material particles. If the stress surpasses the yield stress of the material, the particle will crack. The insertion-induced stress can be qualitatively calculated based on classical mechanics equations. ${ }^{35,36}$ Similar to Zhang et al., ${ }^{37}$

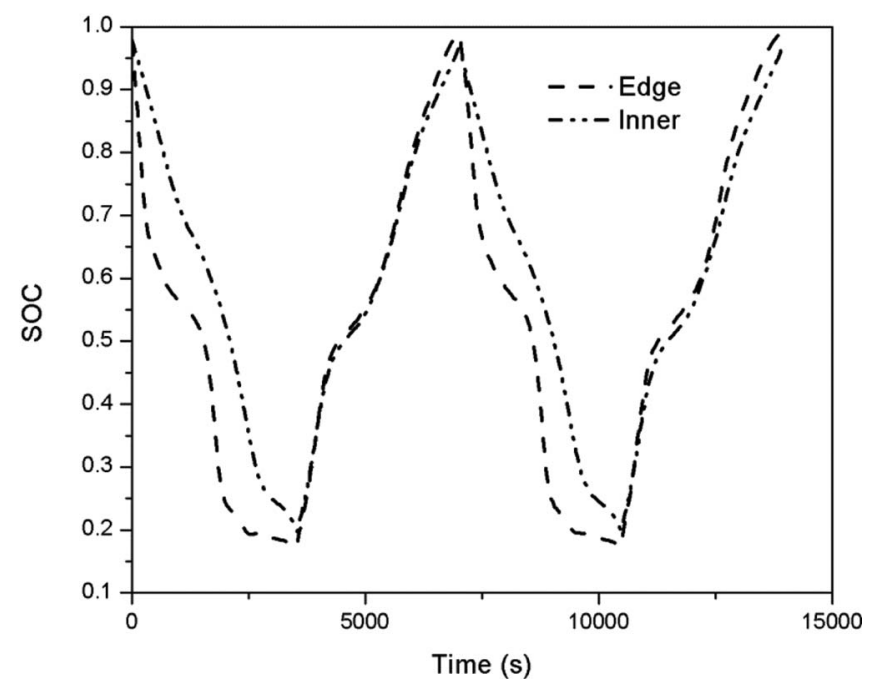

Figure 5. State of charge (SOC) vs. time at the edge point (Edge) as well as at the inner point (Inner) of cathode during $1 \mathrm{C}$ charge for a cell with a1 $\mathrm{mm}$ anode extension over the cathode.

the insertion-induced stress is estimated by the following equations:

$$
\begin{aligned}
& \sigma_{r}=\frac{2 \Omega E}{3(1-v)}\left[\frac{1}{R_{0}^{3}} \int_{0}^{R_{s}} c r^{2} d r-\frac{1}{r^{3}} \int_{0}^{r} c r^{2} d r\right] \\
& \sigma_{t}=\frac{\Omega E}{3(1-v)}\left[\frac{2}{R_{0}^{3}} \int_{0}^{R_{s}} c r^{2} d r-\frac{1}{r^{3}} \int_{0}^{r} c r^{2} d r-c\right]
\end{aligned}
$$

where $\sigma_{r}$ and $\sigma_{t}$ are the radial and tangential components of the stress tensor, respectively, $\Omega$ is the partial molar volume of LMO, E is Young's modulus, and $v$ is Poisson's ratio. As shown in our previous work, ${ }^{38}$ the maximum radial stress and the maximum tangential stress are located at the particle center $(r=0)$ and the particle surface $\left(r=R_{s}\right)$, respectively. We also found that if we neglect the stressdriven diffusion, the values of the maximum radial stress and the maximum tangential stress are very close. In the following discussion, we only show the maximum tangential stress (the surface tangential stress: $\left.\sigma_{t, \text { surf }}=\sigma_{t}\left(r=R_{0}\right)\right)$. The maximum tangential stress on the particle surface from Eq. 19 can be written as:

$$
\sigma_{t, \text { surf }}=\frac{\Omega E}{3(1-v)}\left(c_{s, \text { avg }}-c_{s, \text { surf }}\right)
$$

Thus, we can estimate the tangential stress on the particle surface from our current model without modification. Although the stressdriven diffusion is not included in our model, it is still a good reflection of insertion-induced stress. It has been shown that the concentration profile within particles does not change much without stress-driven diffusion in low C-rate ranges. ${ }^{35,37}$

The estimated insertion-induced stress in magnitude (during the cell cycling shown in Figure 5) as a function of time is presented in Figure 6. During charge (e.g. 0-3600 s) the particles at the edge are found to suffer a much higher maximal stress than the particles at the interior. In contrast, during discharge (e.g. 3600-7200 s) the insertioninduced stresses are very close for the particles at the electrode edge and the interior. Since the particle fracture is related to the maximal stress the particle has suffered, Figure 6 shows that the particle fracture potentially occurs at the electrode edge. It can be found that the insertion-induced stress is related to the SOC as shown in Figure 5. During charge, the SOC vs. time curve in Figure 5 has a higher slope (in magnitude) at the edge point than at the inner point. At the same time, the particle shows larger stress at the electrode edge in Figure 6. On the other hand, during discharge the SOC change at the edge is almost identical to that at the inner part and the stresses are similar in both places. The SOC change rate at a given point is determined by the 


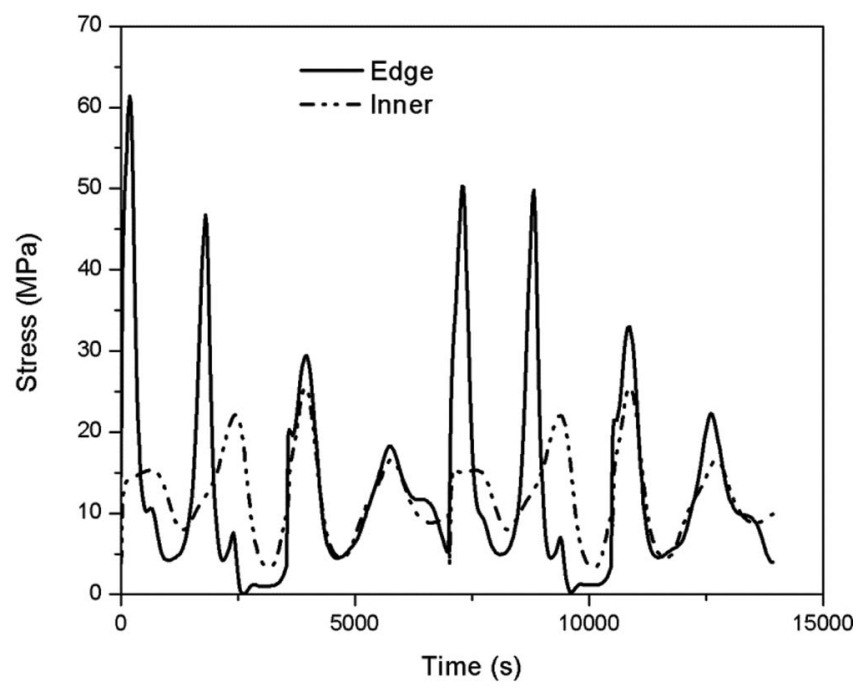

Figure 6. The estimated insertion-induced stress as function of time at the edge point (Edge) as well as at the inner point (Inner) of the cathode during a $1 \mathrm{C}$ charge for a cell with a $1 \mathrm{~mm}$ anode extension over the cathode.

pore wall flux on the particle surface. Our previous study showed that, in the porous electrode, the insertion-induced stress is proportional to the pore wall flux on the particle surface, which is similar to the case that, in a single particle model, the insertion-induced stress is proportional to the applied current. ${ }^{38}$

Figures 4-6 together suggest that the degradation of LMO electrode would be more pronounced at the edge due to the following effects: the larger potential difference, the wider SOC range, and the higher insertion-induced stress. The model-simulated inhomogeneous degradation mentioned above is in agreement with the experimental observation by Cai et al. ${ }^{21}$ They reported that LMO degradation was predominantly at the electrode edge.

Next, the effects of the adjustable design parameters and the electrolyte properties on the degradation at the cathode edge were investigated. The case studies below include varying the following parameters: the anode extension, the capacity ratio, the porosity, the electrode thickness, the diffusion coefficient in the electrolyte, and the conductivity of the electrolyte. For simplicity, only the predicted potential differences at the edge of cathode are presented in the following parts, since the cycling SOC range and the insertion-induced stress are all related to the potential difference.

Effects of adjustable design parameters. - Figure 7a shows the potential difference at cathode edge during $1 \mathrm{C}$ charge with various extensions of the anode. All the other parameters are held as the same as in the base case $(1 \mathrm{~mm})$, except for the small change in the capacity ratio due to the change in the anode height. As the anode extension increases, the potential difference at the edge of the cathode increases. Therefore, the higher anode extension may increase the electrolyte oxidation at the cathode edge. This indicates that although the high anode extension helps reduce lithium plating at the anode edge, it may cause serious LMO degradation at the cathode edge. If a cell is cathode-limited, such as those for high-power applications, the cell capacity loss will be faster due to loss of LMO. Figure 7a also shows that the anode extension does not affect the charging time. This is because the cell considered here is cathode-limited. Also, the utilization of the extension part of the anode is very low, as discussed earlier. These results highlight the importance of choosing an optimum design of the anode extension length. A good design should not only prevent the lithium plating at the edge of the anode, but also have the least possibility of increasing the degradation at the cathode edge. Moreover, these results indicate that the edge effect due to electrode mismatch and the loss of LMO at the edge would enhance each other, causing serious damage that penetrates into the electrode. As shown
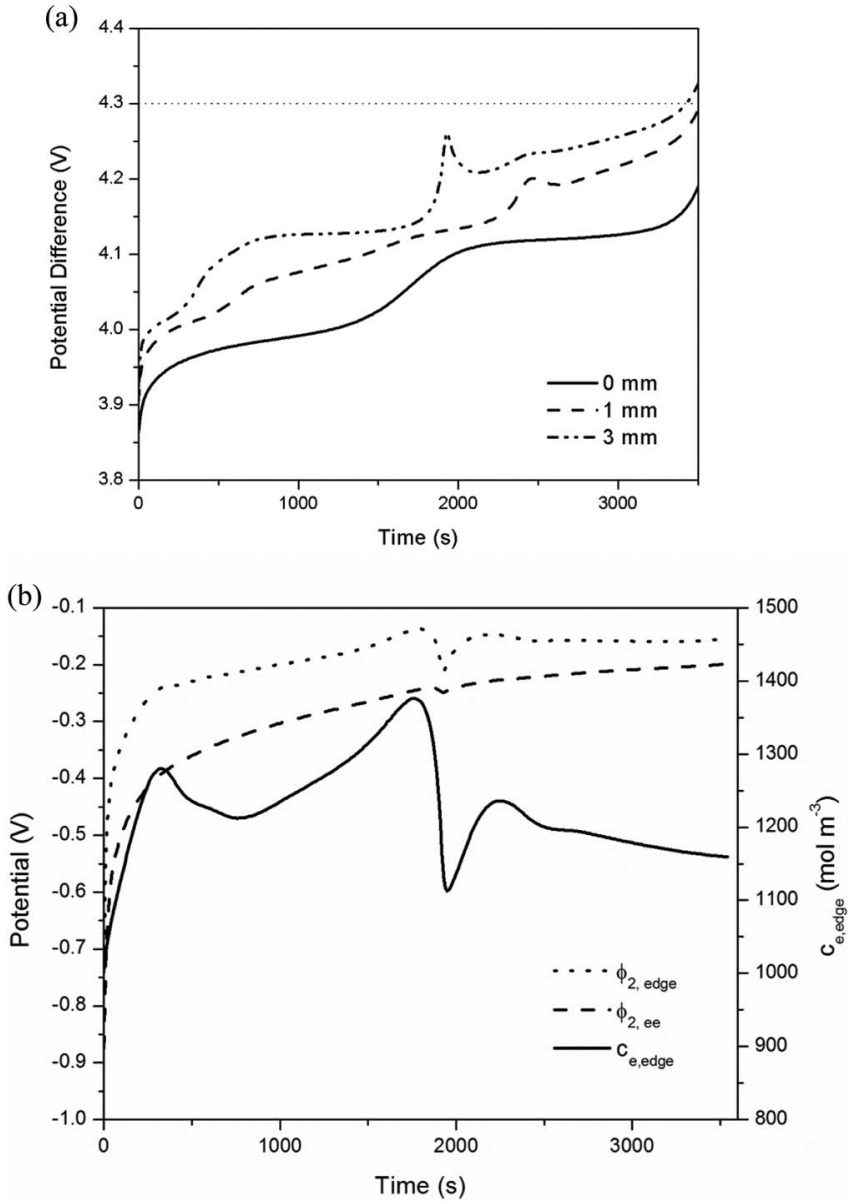

Figure 7. (a) The potential difference at the edge of cathode versus time during a $1 \mathrm{C}$ charge for a cell with various anode extension lengths over cathode. (b) Electrolyte potential and lithium ion concentration profiles during charging for a cell with $3 \mathrm{~mm}$ anode extension over the cathode. The edge point refers to point $\mathrm{C} 1$ in Figure 1. The extra electrolyte refers to point $\mathrm{C} 3$ in Figure 1.

in Figures $2 c$ and $3 b$, the edge effect is limited in a narrow area near the edge, however, Cai et al..$^{21}$ reported that the serious degradation of LMO was observed at $10 \mathrm{~mm}$ from edge after 400 cycles. As discussed earlier, the electrode mismatch would lead to the loss of active LMO at the electrode edge. In turn, this increases the mismatch of the electrodes. Furthermore, the increase of mismatch of the electrodes promotes the degradation of active LMO at the electrode edge, as shown in Figure 7a. Therefore, the combination of the loss of active LMO and the increasing extent of electrode mismatch will cause the degradation of the LMO to move toward the interior of the cathode.

It should be noted that when the cathode is shorter than the anode, there is an unusual peak on the potential difference curve of the electrode edge, which is not shown on the potential difference curve of the inner points. This kind of peak has been reported in the previous experimental work. ${ }^{10,11}$ This peak is due to the properties of the electrode geometry (e.g., thickness, porosity) and the electrolyte. As discussed before, the distribution of potential difference in the cell is mainly caused by electrolyte potential. Here, we only focus on the change in the electrolyte potential during charging. The potential difference between the extra electrolyte area, $\phi_{2, e e}$, and the potential at cathode edge, $\phi_{2, e d g e}$, can be approximately calculated by (according to Eq. 4):

$$
\phi_{2, e e}-\phi_{2, e d g e}=\frac{2 R T\left(1-t^{+}\right)}{F}\left[\ln c_{e, e e}-\ln c_{e, e d g e}\right]
$$

The $\phi_{2, \text { edge }}$ can be determined by $\phi_{2, e e}$ and the concentration difference between the edge point, $c_{e, e d g e}$, and the extra electrolyte area, 


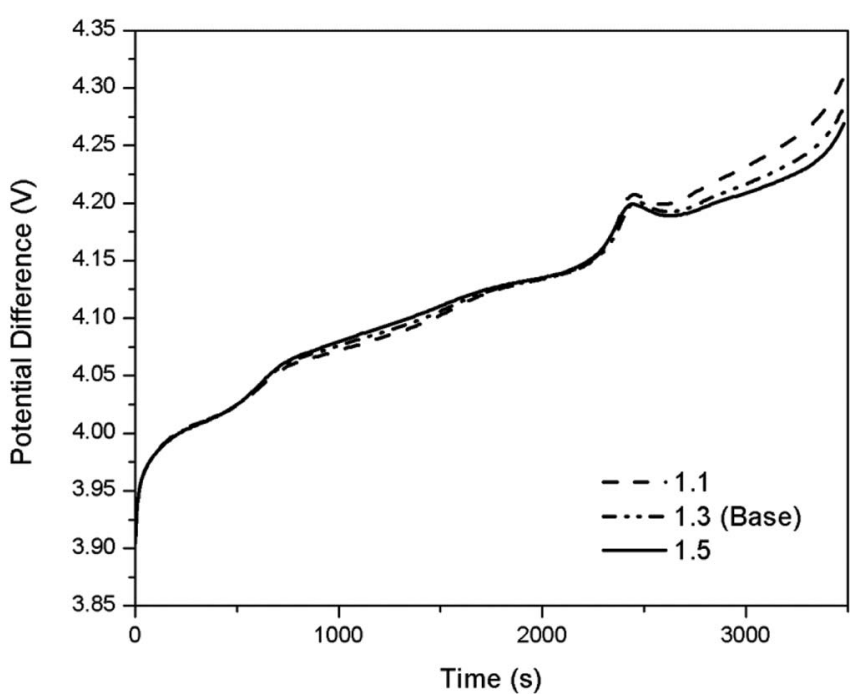

Figure 8. The effect of capacity ratio electrode on the magnitude of potential difference at the edge of cathode for a cell with a $1 \mathrm{~mm}$ anode extension over the cathode.

$c_{e, e e}$, which is almost constant during the charging process. Figure $7 \mathrm{~b}$ shows the simulation results of $\phi_{2, e d g e}, \phi_{2, e e}$ and $c_{e, e d g e}$, for a cell with a $3 \mathrm{~mm}$ anode extension over the cathode. During time 1800-2000 s, $\phi_{2, e e}$ increases slightly and $c_{e, e d g e}$ decreases significantly. Consequently, $\phi_{2, \text { edge }}$ decreases due to the decrease in $c_{e, \text { edge }}$. The decrease in $c_{e, e d g e}$ is because LMO at the edge is more charged than at the inner cathode during this time range. On the other hand, as the $\phi_{2, \text { edge }}$ decreases, the generation rate of lithium ions will increase at the edge area, and then the $c_{e, e d g e}$ will rise again, but there is some time lag. Through this competing process, the peak in the potential difference at the edge of the cathode is expected.

Figure 8 shows the effect of capacity ratio on the cathode performance. The capacity ratio is defined as the ratio of the anode capacity to the cathode capacity. The capacity ratio was adjusted by changing the thickness of the anode, and other design parameters were kept the same as those in the base case (capacity ratio $=1.3$ ). As indicated in Figure 8, the capacity ratio has no significant influence on the potential difference at the edge of the cathode.

The effect of the electrode porosity on the potential difference at the edge of the cathode is illustrated in Figure 9. Various porosity

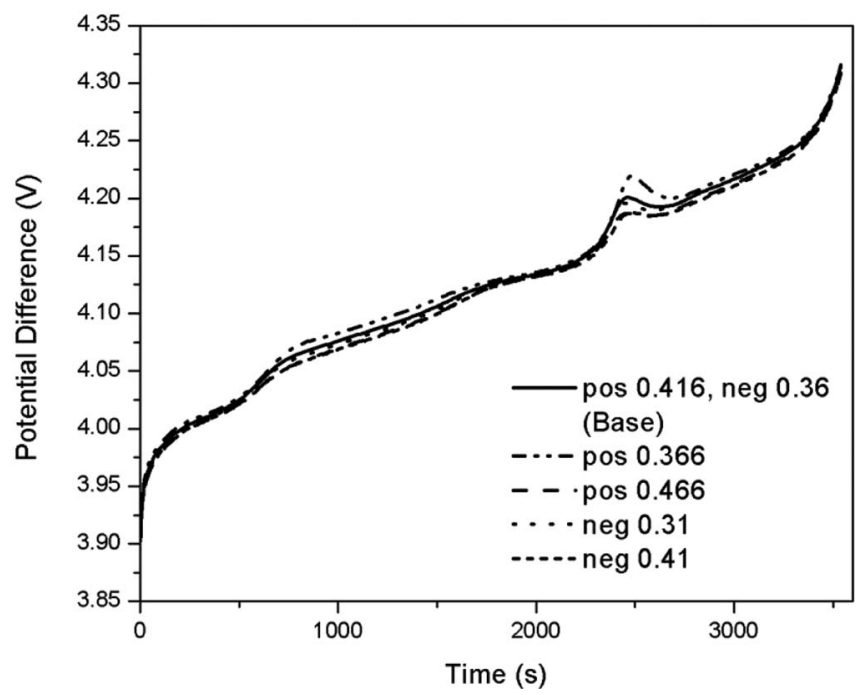

Figure 9. The effect of electrode porosity on the magnitude of potential difference at the edge of the cathode for a cell with a $1 \mathrm{~mm}$ anode extension over the cathode.

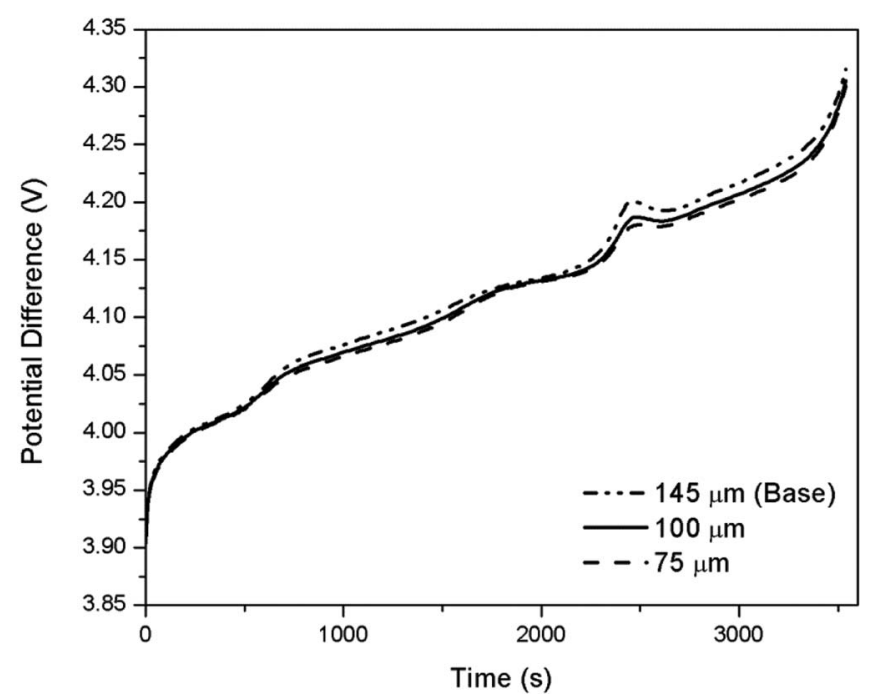

Figure 10. The effect of thickness of the positive electrode on the magnitude of potential difference at the edge of cathode for a cell with a $1 \mathrm{~mm}$ anode extension over the cathode.
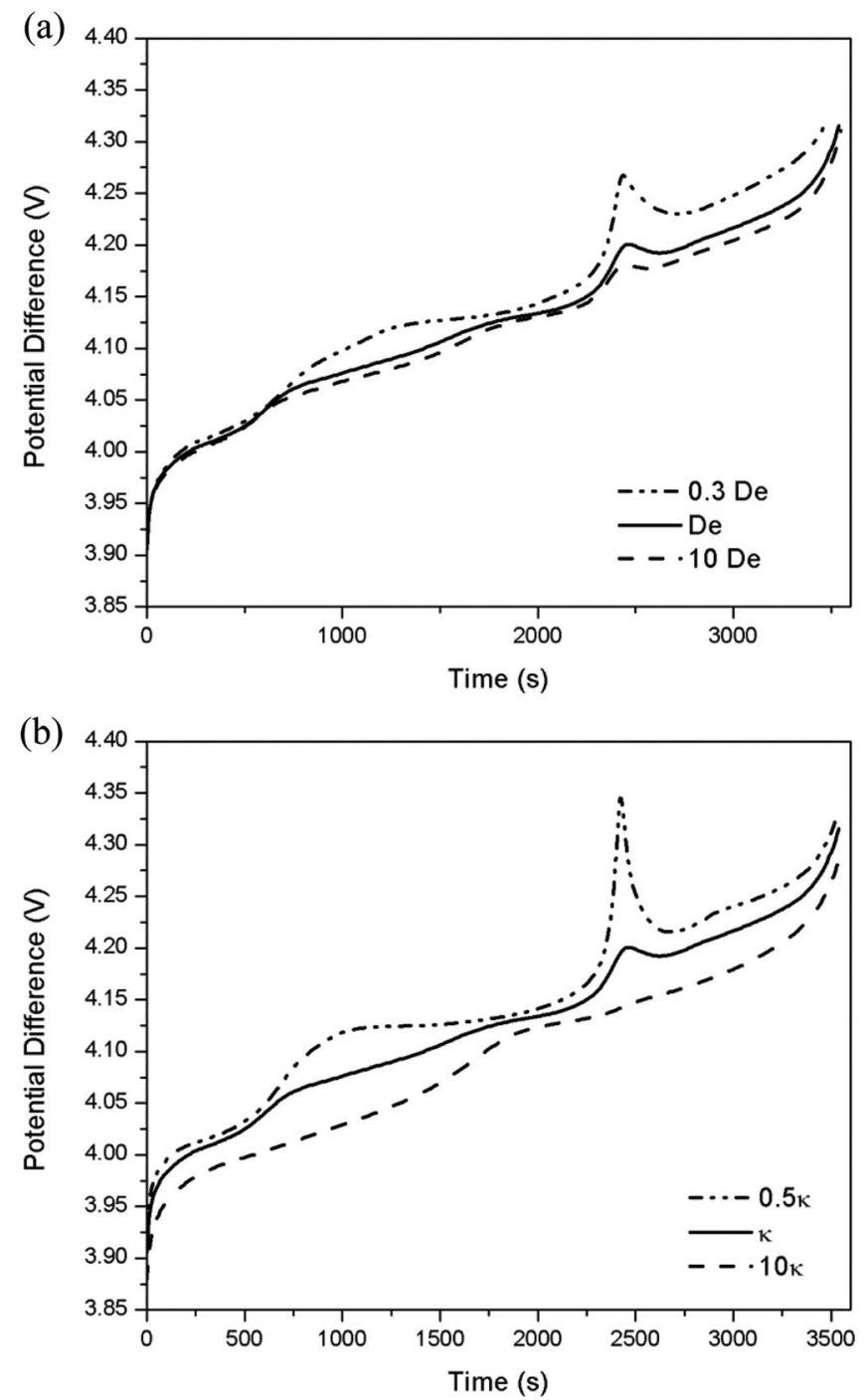

Figure 11. Investigate the effect of electrolyte properties on the over-potential behavior at the edge of cathode (a) the effect of lithium ion solution diffusion coefficient; (b) the effect of electrolyte conductivity. 
values of the cathode and the anode were investigated. The capacity ratio was kept constant for the cases with various porosities by adjusting the electrode thickness. The other parameters were kept the same as in the base case $\left(\epsilon_{2, \mathrm{p}}=0.416, \epsilon_{2, \mathrm{n}}=0.63\right)$. As shown in Figure 9, the potential difference does not change significantly as the porosity changes in the electrode.

Figure 10 shows the effect of the thickness of the cathode on the potential difference at the edge of the cathode. The thickness of the anode was changed accordingly with the change in the thickness of the cathode to keep the capacity ratio constant. All other parameters are the same as those in the base case $(145 \mathrm{um})$. The charge rate is $1 \mathrm{C}$. Here the applied current of $1 \mathrm{C}$ changes accordingly with the change in the thickness of the cathode. Figure 10 indicates that the potential difference at the edge of the cathode is not strongly dependent on the electrode thickness.

Influence of electrolyte properties. - We also investigated the effect of electrolyte properties on the potential difference at the cathode edge, although the improvement of these intrinsic electrolyte properties is difficult. Figure 11 shows the effects of varying the lithium ion diffusion coefficient in the electrolyte (a) and the electrolyte conductivity (b) on the potential difference at the edge of the cathode. It can be observed from Figure 11 that as these two properties increase, the potential difference at the cathode edge decreases. This is because an increase in the diffusion coefficient and the conductivity in the electrolyte reduces the polarization loss in the electrolyte. Therefore, the potential difference decreases. However, the improvement in these electrolyte properties is limited, especially for the increase of the diffusion coefficient. Together with the case studies presented above, it can be concluded that the cathode edge effect is dominated by the extent of mismatch between the cathode and the anode. It should be noted that designs that increase the capacity ratio, the diffusivity, and the ionic conductivity of the electrolyte will reduce the lithium plating on the anode. ${ }^{8,9}$

\section{Conclusions}

A two-dimensional model was developed to understand the inhomogeneous degradation of LMO electrode in the large-format cells. First, this model was used to investigate the effect of anode extension on the lithium plating at the edge of the anode. The anode extension can significantly reduce the possibility of lithium plating on the anode. However, the utilization of the extra part of the anode for lithium insertion is very low. Also, the anode extension has no effect on the behavior of the bulk electrodes. Next, the model was used to predict the potential difference, the state of charge, and the maximum tangential stress at the edge and the inner part of the cathode. From our simulation, it was found that although the design of anode extension over cathode helps prevent the lithium plating at the edge of the anode, it will increase the potential difference, cycling SOC range, and insertion-induced stress for particles near the edge of the cathode. Therefore, the loss of LMO is more pronounced near the electrode edge as in the experimental observations. Simulations were also conducted with different adjustable design parameters (anode extension length, capacity ratio, porosity, and electrode thickness) and electrolyte properties (diffusion coefficient and conductivity). Among them, the over-potential behavior of cathode is most sensitive to the extent of electrode mismatch. The larger anode extension would increase the potential of LMO degradation at the edge of cathode. Therefore, we point out that a longer extension is not always better for the improvement of the cell life. An optimum design of anode extension length should be chosen.

\section{Appendix}

The effective ionic conductivity and diffusion coefficient in the binary electrolyte are determined by the following equations, respectively:

$$
\begin{gathered}
\kappa_{e f f, i}=\varepsilon_{i}^{\text {brugg }_{i}} \kappa, \quad i=p, s, n \\
D_{e, e f f, i}=\varepsilon_{i}^{\text {brugg }_{i}} D_{e}, \quad i=p, s, n
\end{gathered}
$$

The concentration-dependent ionic conductivity and the diffusion coefficient in the binary electrolyte are given by: ${ }^{39}$

$\kappa=10^{-4} \times c_{e}\left(\begin{array}{l}-10.5+0.668 \times 10^{-3} c_{e}+0.494 \times 10^{-6} c_{e}^{2}+0.074 T \\ -1.78 \times 10^{-5} c_{e} T-8.86 \times 10^{-10} c_{e}^{2} T-6.96 \times 10^{-5} T^{2}+2.80 \times 10^{-8} c_{e} T^{2}\end{array}\right)^{2}$

$$
D_{e}=10^{-4} \times 10^{-4.43-} \frac{54}{T-229-5.0 \times 10^{-3} c_{e}}-0.22 \times 10^{-3} c_{e}
$$

The effective conductivity in the solid phase is defined as

$$
\sigma_{e f f, i}=\varepsilon_{1, i} \sigma, \quad i=p, n
$$

The open circuit potentials for the $\mathrm{LiMn}_{2} \mathrm{O}_{4}$ cathode as functions of state of charge are given by: ${ }^{40}$

$$
\begin{array}{r}
U_{L M O}=4.19829+0.0565661 \tanh \left(-14.5546 \theta_{L M O}+8.60942\right) \\
-0.0275479\left(\frac{1}{\left(0.998432-\theta_{L M O}\right)^{0.492465}}-1.90111\right) \\
-0.157123 \exp \left(-0.04738 \theta_{L M O}^{8}\right)+0.810239 \exp \left(-40\left(\theta_{L M O}-0.133875\right)\right) \quad \text { [A6] }
\end{array}
$$

The open circuit potentials for the carbon anode as functions of state of charge are given by: ${ }^{7}$

$$
\begin{aligned}
U_{C}= & 0.7222+0.13868 \theta_{C}+0.028952 \theta_{C}^{0.5}-\frac{0.017189}{\theta_{C}}+\frac{0.0019144}{\theta_{C}{ }^{1.5}} \\
& +0.28082 \exp \left[15\left(0.06-\theta_{C}\right)\right]-0.79844 \exp \left[0.44649\left(\theta_{C}-0.92\right)\right]
\end{aligned}
$$

where the SOC, $\theta$, is defined by:

$$
\theta=\frac{c_{s, \text { surf }}}{c_{\max }}
$$

\section{List of Symbols}

a specific surface area, $\mathrm{m}^{2} \mathrm{~m}^{-3}$

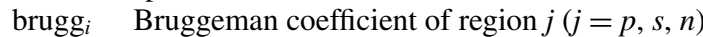

$c_{e} \quad$ concentration of lithium ion in the solution, $\mathrm{mol} \mathrm{m} \mathrm{m}^{-3}$

$c_{e}{ }^{0} \quad$ initial concentration of lithium ion in the solution, $\mathrm{mol} \mathrm{m}^{-3}$

$c_{s} \quad$ concentration of lithium ion in the intercalation particles, mol m $\mathrm{m}^{-3}$

$c_{s, a v g} \quad$ volume-averaged lithium ion concentration in the particles, mol m $\mathrm{m}^{-3}$

$c_{s, \text { surf }} \quad$ surface lithium ion concentration of particles, $\mathrm{mol} \mathrm{m}^{-3}$

$c_{s}{ }^{0} \quad$ initial concentration of lithium ion in the intercalation particles of the electrode, mol $\mathrm{m}^{-3}$

$\mathrm{c}_{\max }$ maximum concentration of lithium ion in the intercalation particle, $\mathrm{mol} \mathrm{m} \mathrm{m}^{-3}$

$D_{e} \quad$ salt diffusion coefficient, $\mathrm{m}^{2} \mathrm{~s}^{-1}$

$D_{s} \quad$ Lithium ion diffusion coefficient in the intercalation particles of the electrode, $\mathrm{m}^{2} \mathrm{~s}^{-1}$

F $\quad$ Faraday's constant, $96487 \mathrm{C} \mathrm{equiv}^{-1}$

$I_{a p p} \quad$ applied current density, $\mathrm{A} \mathrm{m}^{-2}$

$J \quad$ pore wall flux of lithium ion, mol m $\mathrm{m}^{-2} \mathrm{~s}^{-1}$

$k_{L i} \quad$ Lithium ion intercalation/de-intercalation reaction rate constant, $\mathrm{m}^{2.5} \mathrm{~mol}^{-0.5} \mathrm{~s}^{-1}$

$L_{c c} \quad$ thickness of current collector, $\mathrm{m}$

$L_{p} \quad$ thickness of positive electrode, $\mathrm{m}$

$L_{s} \quad$ thickness of separator, $m$

$r \quad$ radial coordinate, $m$

$R \quad$ universal gas constant, $\mathrm{J} \mathrm{mol}^{-1} \mathrm{~K}^{-1}$

$R_{s} \quad$ radius of electrode particle, $\mathrm{m}$

SOC state of charge

$q_{s, a v g} \quad$ volume averaged flux in the particle, $\mathrm{mol} \mathrm{m}^{-4}$

$t_{+}^{0}$

$\stackrel{+}{T}$

Lithium ion transference number in the electrolyte

environment temperature, $\mathrm{K}$

$U$ open-circuit potential, $\mathrm{V}$

$V_{\text {cell }} \quad$ cell potential, $\mathrm{V}$

$X, Y \quad$ spatial coordinate, $\mathrm{m}$

\section{Greek letters}

$\alpha_{a} \quad$ anodic transfer coefficient

$\alpha_{c} \quad$ cathodic transfer coefficient

$\varepsilon_{1} \quad$ volume fraction of the solid phase 
$\varepsilon_{2} \quad$ porosity

$\theta$ dimensionless concentration of lithium ion in the intercalation particle $\left(\theta=c_{s, \text { surf }} / c_{\max }\right)$

$\theta^{0} \quad$ initial dimensionless concentration of lithium ion in the intercalation particles

$\kappa \quad$ ionic conductivity of the electrolyte, $\mathrm{S} \mathrm{m}^{-1}$

$\sigma \quad$ electronic conductivity of the solid phase, $\mathrm{S} \mathrm{m}^{-1}$

$\sigma_{r} \quad$ radial component of stress, $\mathrm{N} \mathrm{m}^{-2}$

$\sigma_{t} \quad$ tangential component of stress, $\mathrm{N} \mathrm{m}^{-2}$

$\phi_{1} \quad$ solid phase potential, V

$\phi_{2} \quad$ solution phase potential, $\mathrm{V}$

$\eta \quad$ overpotential, $\mathrm{V}$

\section{Subscripts}

a anode

c cathode

cc current collector

ee extra electrolyte area

eff effective

max maximum

n negative electrode

$\mathrm{p} \quad$ positive electrode

$\mathrm{r}$ radial direction

s separator

$\mathrm{t}$ tangential direction

LMO $\quad \mathrm{LiMn}_{2} \mathrm{O}_{4}$

$\mathrm{C}$ carbon
7. P. Arora, M. Doyle, and R. E. White, J Electrochem Soc, 146, 3543 (1999).

8. M. Tang, P. Albertus, and J. Newman, J Electrochem Soc, 156, A390 (2009).

9. K. Eberman, P. M. Gomadam, J. Jain, and E. Scott, ECS Transactions, 25, 47 (2010).

10. E. Scott, G. Tam, B. Anderson, and C. Schmidt In The Electrochemical Society Meeting 2003.

11. E. Scott, G. Tam, B. Anderson, and C. Schmidt In The Electrochemical Society Meeting Orlando, FL, 2003, Vol. Paper 1282

12. W. Choi and A. Manthiram, J Electrochem Soc, 153, A1760 (2006).

13. D. H. Jang, Y. J. Shin, and S. M. Oh, J Electrochem Soc, 143, 2204 (1996).

14. Y. L. Dai, L. Cai, and R. E. White, J Electrochem Soc, 160, A182 (2013).

15. H. F. Wang, Y. I. Jang, B. Y. Huang, D. R. Sadoway, and Y. T. Chiang, J Electrochem Soc, 146, 473 (1999).

16. M. R. Lim, W. I. Cho, and K. B. Kim, J Power Sources, 92, 168 (2001).

17. S. Bhattacharya, A. R. Riahi, and A. T. Alpas, J. Power Sources, 196, 8719 (2011).

18. R. Deshpande, M. Verbrugge, Y. T. Cheng, J. Wang, and P. Liu, J Electrochem Soc, 159, A1730 (2012).

19. R. Kostecki and F. McLarnon, J Power Sources, 119, 550 (2003).

20. J. Christensen, J Electrochem Soc, 157, A366 (2010).

21. L. Cai, K. An, Z. L. Feng, C. D. Liang, and S. J. Harris, J Power Sources, 236, 163 (2013).

22. G. Sikha, B. N. Popov, and R. E. White, J Electrochem Soc, 151, A1104 (2004).

23. Y. Chen and J. W. Evans, J Electrochem Soc, 140, 1833 (1993).

24. D. R. Baker and M. W. Verbrugge, J Electrochem Soc, 146, 2413 (1999).

25. J. N. Harb and R. M. LaFollette, J Electrochem Soc, 146, 809 (1999).

26. G. H. Kim, K. Smith, K. J. Lee, S. Santhanagopalan, and A. Pesaran, J Electrochem Soc, 158, A955 (2011).

27. M. Guo and R. E. White, J. Power Sources, 221, 334 (2013).

28. A. Awarke, S. Pischinger, and J. Ogrzewalla, J Electrochem Soc, 160, A172 (2013).

29. J. Wu, V. Srinivasan, J. Xu, and C. Y. Wang, J Electrochem Soc, 149, A1342 (2002).

30. M. Doyle, T. F. Fuller, and J. Newman, J Electrochem Soc, 140, 1526 (1993)

31. T. F. Fuller, M. Doyle, and J. Newman, J Electrochem Soc, 141, 1 (1994).

32. L. Cai and R. E. White, J Power Sources, 196, 5985 (2011).

33. V. R. Subramanian, V. D. Diwakar, and D. Tapriyal, J Electrochem Soc, 152, A2002 (2005).

34. M. M. Thackeray, Y. Shao-Horn, A. J. Kahaian, K. D. Kepler, J. T. Vaughey, and S. A. Hackney, Electrochem Solid St, 1, 7 (1998).

\section{References}

1. M. M. Thackeray, C. Wolverton, and E. D. Isaacs, Energ Environ Sci, 5, 7854 (2012).

2. M. Wohlfahrt-Mehrens, C. Vogler, and J. Garche, J Power Sources, 127, 58 (2004).

3. J. C. Burns, A. Kassam, N. N. Sinha, L. E. Downie, L. Solnickova, B. M. Way, and J. R. Dahn, J Electrochem Soc, 160, A1451 (2013).

4. A. J. Smith, J. C. Burns, D. Xiong, and J. R. Dahn, J Electrochem Soc, 158, A1136 (2011).

5. M. Broussely, S. Herreyre, P. Biensan, P. Kasztejna, K. Nechev, and R. J. Staniewicz, J Power Sources, 97-8, 13 (2001).

6. P. Ramadass, B. Haran, P. M. Gomadam, R. White, and B. N. Popov, J Electrochem Soc, 151, A196 (2004).
35. J. Christensen and J. Newman, Journal of Solid State Electrochemistry, 10, 293 (2006).

36. J. Christensen and J. Newman, J Electrochem Soc, 153, A1019 (2006).

37. X. C. Zhang, W. Shyy, and A. M. Sastry, J Electrochem Soc, 154, A910 (2007).

38. Y. L. Dai, L. Cai, and R. E. White, J. Power Sources, 247, 365 (2014).

39. L. O. Valoen and J. N. Reimers, J Electrochem Soc, 152, A882 (2005).

40. M. Doyle, J. Newman, A. S. Gozdz, C. N. Schmutz, and J. M. Tarascon, J Electrochem Soc, 143, 1890 (1996).

41. P. Arora, M. Doyle, A. S. Gozdz, R. E. White, and J. Newman, J Power Sources, 88, 219 (2000).

42. K. Kumaresan, G. Sikha, and R. E. White, J Electrochem Soc, 155, A164 (2008).

43. P. Albertus, J. Christensen, and J. Newman, J Electrochem Soc, 156, A606 (2009). 